\title{
Sigmoid fixation associated with rectopexy using a laparoscopic approach could prevent relapse of rectal prolapse in pediatric patients with spinal dysraphia
}

\author{
Fernando Montes-Tapia ${ }^{a, *}$, Idalia Cura-Esquivel ${ }^{b}$, Ulises Garza-Luna ${ }^{a}$, \\ Guillermo Martínez-Flores ${ }^{a}$, Gerardo Muñoz-Maldonado ${ }^{a}$, Valdemar Abrego-Moya ${ }^{c}$
}

\author{
a Pediatric Surgery, Hospital Universitario “Dr José E. González,” Universidad Autónoma de Nuevo León, \\ Madero y Gonzalitos s/n, Monterrey, Nuevo León 64460, México \\ ' Pediatric Gastroenterology, Hospital Universitario “Dr José E. González,” Universidad Autónoma de Nuevo León, \\ Madero y Gonzalitos s/n, Monterrey, Nuevo León 64460, México \\ 'Pediatric Department Hospital Universitario “Dr José E. González,” Universidad Autónoma de Nuevo León, \\ Madero y Gonzalitos s/n, Monterrey, Nuevo León 64460, México
}

Received 27 September 2007; revised 25 February 2008; accepted 25 February 2008

Key words:

Rectal prolapse;

Spinal dysraphia;

Laparoscopic rectopexy;

Sigmoid fixation

\begin{abstract}
Recurrent rectal prolapse, resistant to medical treatment, is an indication for surgical treatment. Patients with spinal dysraphia frequently have already been treated by sclerotherapy or other surgical techniques, but unsuccessfully.

Methods: We present 2 patients, who underwent laparoscopic rectopexy, with spinal dysraphia and complete rectal prolapse relapse after conservative treatment. In these patients, we performed, as an additional technique, fixation of the rectosigmoid to avoid recurrence by invagination or prolapse of the anterior wall.

Results: Follow-up at 14 and 11 months, respectively, did not find any recurrence.

Conclusion: We suggest that laparoscopic rectopexy with sigmoid fixation should be considered as an alternative for the treatment for patients with spinal dysraphia and rectal prolapse to avoid recurrence. (C) 2008 Elsevier Inc. All rights reserved.
\end{abstract}

Rectal prolapse in pediatric patients is a self-limited illness in most cases. It is frequently a partial prolapse of the mucosa, generally idiopathic, unlike complete rectal prolapse in adults that involves protrusion of all the layers [1]. Spina bifida is a congenital defect that includes a wide range

* Corresponding author. Pediatric Surgery, Hospital Universitario "Dr José E. González,” Universidad Autónoma de Nuevo León, Madero y Gonzalitos s/n, Monterrey, Nuevo León 64460, México. Tel.: +52 81 82485421

E-mail address: ffmt@yahoo.com (F. Montes-Tapia). of malformations, from occult spina bifida in its mild form to myelomeningocele in its most severe form [2,3]. In these patients, rectal prolapse is usually complete, persistent, and commonly recurrent in spite of medical treatment. Relapse is an indication for surgery [4]. The incidence of rectal prolapse associated to spinal dysraphia that requires surgical treatment varies in published series from $5.3 \%$ to $40 \%$ [5-8]. Multiple surgical techniques have been described as successful treatment of rectal prolapse; [9-12] however, recurrence is frequent in patients with associated neuromuscular pathology [8]. 


\section{Material and methods}

\subsection{Case 1}

The patient is an 18-month-old full-term male born by cesarean delivery, diagnosed with lumbar myelomeningocele and a type II Arnold-Chiari malformation treated surgically at birth by lumbar plasty and the placement of a ventriculoperitoneal shunt. At 3 months, a tracheostomy and Nissen fundoplication were performed. The patient presented complete rectal prolapse resistant to medical treatment (persistent prolapse) at 4 months of age. Medical treatment before surgery included diet and laxatives as well as manual reduction of prolapse. The patient received treatment for 6 months and then was lost to follow-up for 8 months. The patient returned for consultation because of persistent prolapse. Because of this, rectopexy and sigmoid fixation were performed laparoscopically.

\subsection{Case 2}

A 12-month-old full-term male was diagnosed at age of 9 months with complete rectal prolapse and occult spina bifida. When we saw this patient in our service for the first time, he had received medical treatment for 1 month previously at another center. The patient received 3 months of diet and laxatives as well as manual reduction at our

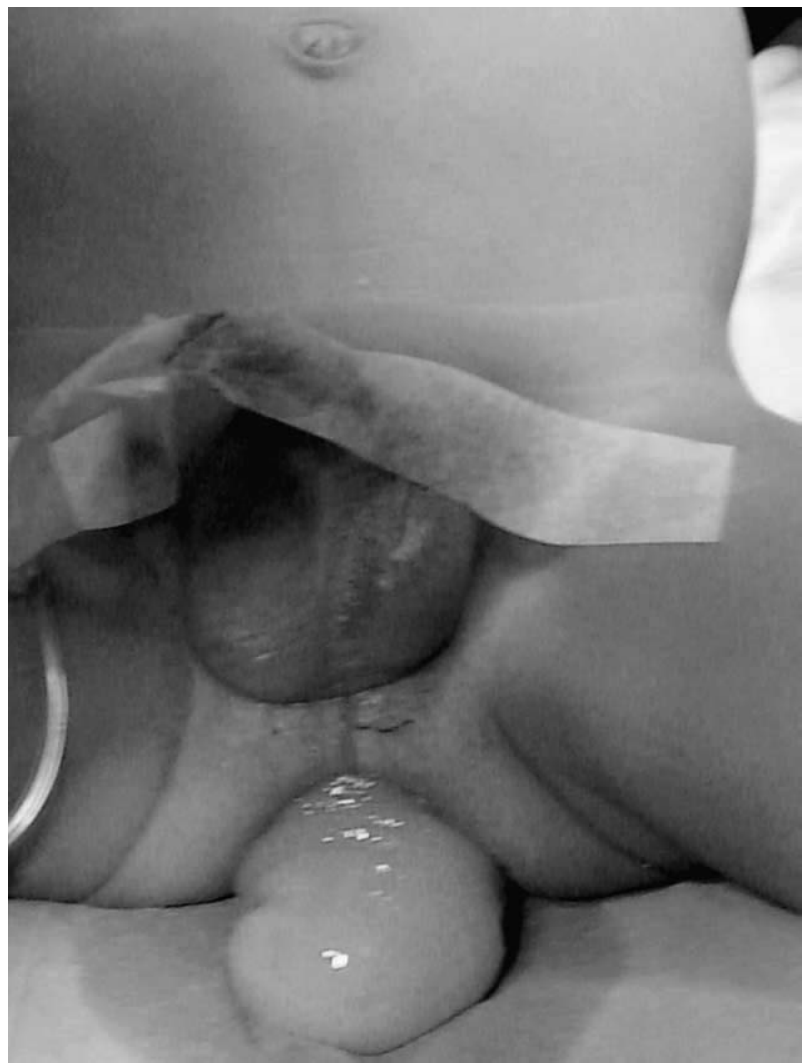

Fig. 1 Case 2 with complete prolapse.

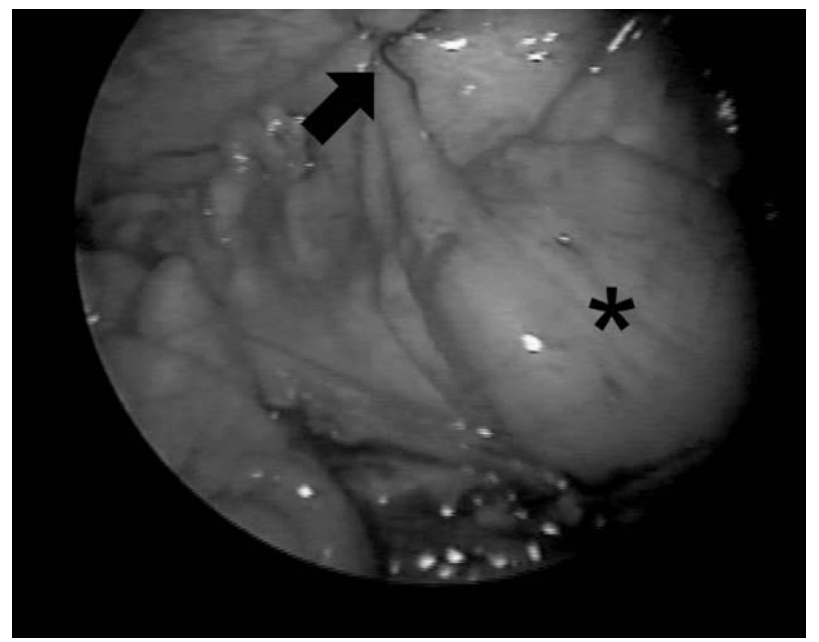

Fig. 2 Sigmoid fixation (arrow). Rectum (asterisk).

service, but persistence of rectal prolapse and bleeding in spite of manual reduction motivated laparoscopic rectopexy and sigmoid fixation (Fig. 1).

Preoperative workup included rectal examination; chest, abdomen, and spinal x-rays; fecal examination in search of parasites, and electrolytes in sweat in both cases. All results of preoperative examinations were negative, except for the spinal defects mentioned before.

\subsection{Surgical technique}

Under general anesthesia, the patient is placed in the dorsal position. Pneumoperitoneum is created by the open transumbilical technique with a $\mathrm{CO}_{2}$ pressure of $10 \mathrm{~mm}$ $\mathrm{Hg}$. Four ports of $5 \mathrm{~mm}$ and a $5-\mathrm{mm} 30^{\circ}$ laparoscope (Storz, Tuttingen, Germany) are used. The laparoscope is placed in the umbilicus, 2 paraumbilical trocars at the level of the right and left mid clavicular line and 1 in the right lower quadrant. The prolapsed colon is reduced, and the peritoneum is bilaterally incised at the level of the sacral

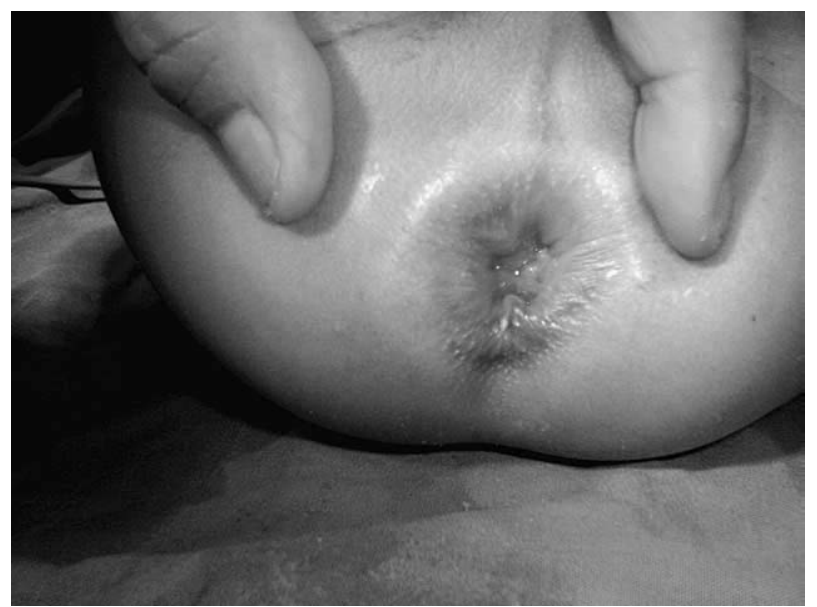

Fig. 3 Postoperative aspect of case 2 . 
promontory. Dissection is done in the retrorectal space to the pelvic floor, visualizing both ureters and the iliac vessels. The rectum is fixed to the sacral promontory with 2 intracorporeal points of nonabsorbable 2-0 suture. In case 1 at the end of the procedure, it was noticed that the anterior border of the rectum descended into the pelvic cavity partially prolapsing the anterior border of the anus. For this reason, the anterior border of the rectosigmoid was fixed to the sidewall of the left side of the pelvic hollow at the level of the sacrum with 2 points of the same type of suture (Fig. 2). In the second case, sigmoid fixation was decided preoperatively because of our experience with the first case to avoid recurrence.

\section{Results}

The surgical time was 120 minutes in case 1 and 70 minutes in case 2, with no intraoperative complications. A laxative diet was started the first day after surgery, and the patients were discharged on the third and fifth postoperative day. After 14 months of follow-up, case 1 presented constipation treated with diet presenting daily passage of stools. Case 2 at 11 months had constipation for 3 months that was treated with laxatives and diet. He is presently treated only with diet and also presents daily passage of stools. Both patients are free of relapse (Fig. 3).

\section{Conclusions}

In adults, the etiology of prolapse is sigmoid distension and looseness more than pelvic floor weakness. In pediatric patients with spinal dysraphias, prolapse is caused by laxity of the musculature of the pelvic floor because of inadequate innervation of the pelvic muscles as well as abnormalities of the sacrum $[4,8,10]$. In these patients, failure of conservative treatment and relapse after surgery or sclerotherapy is usually the rule. Recent studies concerning sclerotherapy report a recurrence rate between $11 \%$ and $17 \%$ associated with high morbidity $[13,14]$. The suggested treatment in pediatric patients is laparoscopic rectopexy to the sacrum, [15-17] with all its benefits of less pain and quick recovery. Patients with spinal dysraphias have an associated lax rectosigmoid, and this can cause partial or total prolapse of the anterior wall, which is not fixed, producing invagination at the level of the rectosigmoid and recurrence by this mechanism $[7,12]$. This is why we propose, in addition to rectopexy, fixation of the anterior border of the rectosigmoid to the lateral wall of the pelvic hollow as a way to avoid relapse. With this fixation, there is no possibility of internal herniation because the sigmoid is in intimal contact with the pelvic floor and adjacent to the lateral wall. Considering this, laparoscopic surgical treatment of rectal prolapse in patients with spinal dysraphias as well as sigmoid fixation should be an alternative to avoid recurrence of prolapse.

\section{Acknowledgments}

The authors wish to acknowledge the kind assistance of Corina Zamfir, MD, and Sergio Lozano, MD, in editing the manuscript.

\section{References}

[1] Stafford PW. Other disorders of the anus and rectum, anorectal function. In: O’Neill JA, Rowe MI, Grosfeld JL, et al, editors. Pediatric Surgery, 5th ed, Vol. II. St. Louis: Mosby-Year Book, Inc.; 1998. p. 1453-4.

[2] Mitchell L, Adzick S, Melchionne J, et al. Spina bifida. Lancet 2004; 364:1885-95.

[3] Peacock WJ. Management of spina bifida, hydrocephalus, central nervous system infections, and intractable epilepsy. In: O'Neill JA, Rowe MI, Grosfeld JL, et al, editors. Pediatric surgery, Vol. II. St Louis, MO: Mosby-Year Book; 1998. p. 1849-52.

[4] Siafakas C, Vottler T, Andersen J. Rectal prolapse in pediatrics. Clin Pediatr 1999;38:63-72.

[5] Sander S, Vural Ö, Ünal M. Management of rectal prolapse in children: Ekehorn's rectosacropexy. Pediatr Surg Int 1999;15:111-4.

[6] Schepens MA, Verhelst AA. Reappraisal of Ekehorn's rectopexy in the management of rectal prolapse in children. J Pediatr Surg 1993;28: 1494-7.

[7] Ashcraft KW, Garred JL, Holder TM, et al. 17-year experience with the posterior repair and suspension. J Pediatr Surg 1990;25:992-4 discussion 994-995.

[8] Alaminos MM, Sánchez LT, Valladares M, et al. La pexia recto-sacra en el tratamiento del prolapso rectal refractario a tratamiento conservador. Cir Pediatr 2000;13:69-72.

[9] Chwals WJ, Brennan LP, Weitzman JJ, et al. Transanal mucosal sleeve resection for the treatment of rectal prolapse in children. J Pediatr Surg 1990;25:715-8.

[10] Lasheen A. Closed rectosacropexy for rectal prolapse in children. Surg Today 2003;33:642-4.

[11] Pearl RH, Ein SH, Churchill B. Posterior sagittal anorectoplasty for pediatric recurrent rectal prolapse. J Pediatr Surg 1989;24:1100-2.

[12] Tsugawa C, Matsumoto Y, Nishijima E, et al. Posterior plication of the rectum for rectal prolapse in children. J Pediatr Surg 1995;30: 692-3.

[13] Fahmy MA, Ezzelarab S. Outcome of submucosal injection of different sclerosing materials for rectal prolapse in children. Pediatr Surg Int 2004;20:353-6.

[14] Shah A, Parikh D, Jawaheer G, et al. Persistent rectal prolapse in children: sclerotherapy and surgical management. Pediatr Surg Int 2005;21:270-3.

[15] Saxena AK, Metzelder ML, Willital GH. Laparoscopic suture rectopexy for rectal prolapse in a 22-month-old child. Surg Laparosc Endosc Percutan Tech 2004;14:33-4.

[16] Politi R, Montupet P. Laparoscopic rectopexy in a child for true prolapse. Pediatr Endosurg Innov Tech 2000;4:147-8.

[17] Okuyama H, Yagi M, Ikegami R, et al. Laparoscopic rectopexy for rectal prolapse in children. Pediatr Endosurg Innov Tech 2002;6:285-8. 